\title{
Candy or apple? How self-control resources and motives impact dietary healthiness in women
}

\author{
Gudrun Sproesser Stefanie Strohbach Harald Schupp Britta Renner
}

\begin{abstract}
A B S T R A C T
People can choose between a virtually endless array of food items rising the question, which factors determine healthy or unhealthy food choice. The present study examines the impact of two contrasting motives for food choice (affect regulation and body weight control) and self-regulatory competences on healthy eating within a sample of women $(N=761)$. The data show that a relative lack of self-regulatory resources combined with a high tendency to regulate negative affect through comfort eating was associated with an unfavorable dietary pattern. Accordingly, a healthy dietary pattern requires not only self-regulatory capacities but also a facilitating motive structure.
\end{abstract}

\section{Introduction}

Today we can choose from a virtually endless array of food items. Modern supermarkets offer up to 60,000 different food items. This variety contributes to how much we eat (Remick, Polivy, \& Pliner, 2009) and it can be also difficult not to choose tempting snack foods but more healthy alternatives on a regular basis. However, which factors determine which food is chosen? In the present study, we ask the question how facilitating (pull) and impeding (push) factors of healthy food choice impact healthy eating.

Recent research suggests that general self-control is an important pull factor for a healthy dietary behavior. Self-control is commonly conceptualized as a general ability to override or alter one's inner responses, as well as to interrupt undesired behavioral tendencies (Tangney, Baumeister, \& Boone, 2004). A recent study showed that adolescents and young adults with a high self-control capacity spent less money on candy, snacks or soft drinks (Junger \& van Kampen, 2010). Conversely, high impulsivity is associated with an enhanced unhealthy snacking behavior (Verplanken, Herabadi, Perry, \& Silvera, 2005) and, in a laboratory setting, impulsive participants bought more high-caloric snack food in a

\footnotetext{
"Acknowledgement: This research was supported by the Federal Ministry of Education and Research (Grant 0315671, granted to Britta Renner \& Harald Schupp).

* Corresponding author.

E-mail addresses: gudrun.sproesser@uni-konstanz.de (G. Sproesser) stefanie.strohbach@uni-konstanz.de (S. Strohbach),

harald.schupp@uni-konstanz.de (H. Schupp), britta.renner@uni-konstanz.de (B. Renner).
}

virtual supermarket when they were hungry (Nederkoorn, Guerrieri, Havermans, Roefs, \& Jansen, 2009). These findings suggest that a general, thus behavior unspecific, capacity for selfcontrol decreases unhealthy food choices.

Another line of research suggests that not only the capacity for self-control impacts healthy food choice but that also the motive or desire for regulating food intake impacts food choice. Specifically, people who demonstrated a high motivation for controlling their body weight showed a higher fiber and a lower fat intake, an increased fruit and vegetable consumption and a lower consumption rate for snacks, fast-foods, and other unhealthy food items (Eertmans, Victoir, Vansant, \& van den Bergh, 2005; Glanz, Basil, Maibach, Goldberg, \& Snyder, 1998: Steptoe \& Wardle, 1999). However, the question how the motivation for regulation on the one hand and the general capacity for regulation on the other hand concur has not been examined, yet.

The motivation and capacity to regulate (unhealthy) food consumption can be conceptualized as pull factors for a regular healthy diet. However, certain factors might counteract these pull factors. Research suggests that an important push factor is the motive to regulate negative affect or emotions by the consumption of unhealthy or high caloric food items. However, while it appears plausible that people, when being in a negative state, choose candy instead of an apple in order to comfort themselves, empirical evidence supporting this notion is mixed. Whereas several studies showed that 'emotional eaters' consumed more energy-dense foods (e.g. Konttinen, Männistö, Sarlio-Lähteenkorva, Silventoinen, \& Haukkala, 2010; Macht \& Mueller, 2007), other studies did not (e.g. Adriaanse, de Ridder, \& Evers, 2011; Habhab, Sheldon, \& Loeb, 2009). One possible reason for the inconsistency of the results is that the urge to cope with negative affective states by comfort 
eating is compensated through a high motivation and capacity for self-control.

One aim of the present study was to examine the relative impact of the behavior specific tendency for body weight control and general capacity for self-control on healthy eating. A further aim was to determine the impact of the two counteracting push (i.e., tendency for emotional eating) and pull (i.e., tendency for body weight control and capacity for self-control) forces on healthy eating.

While previous research mainly focused on specific consumption behaviors (i.e., snacks), the present study employed a more comprehensive and validated measure for healthy eating based on the recommendations of the German Nutritional Society and results from the WHO MONICA study (cf., Winkler \& Döring, 1998, 1995). Since previous research yielded substantial and reliable gender differences with regard to the core study variables such as diet (Konttinen et al., 2010; Renner et al., 2008), body weight and affect regulation motive (Steptoe, Pollard, \& Wardle, 1995), and self-control (Gibson, Ward, Wright, Beaver, \& Delisi, 2010), only women were included in the present study.

\section{Methods}

\section{Participants}

One thousand ninety-eight women answered an online survey Of these, 337 (31\%) filled out less than $75 \%$ of the survey and were therefore excluded from analysis. The remaining 761 women had a mean age of 32.5 years ( $S D=11$; range $15-74$ years). The majority (76\%) had an university-entrance diploma. The average BMI was 23.6 ( $S D=4.6$; range $16.9-47.7)$. Comparing the study sample $(N=761)$ with the drop-out sample $(N=337)$ showed no significant difference in terms of BMI (23.6 vs. 23.8, $t(1094)=-.62$, $p=.53$ ). However the study sample was slightly younger ( $32.5 \mathrm{vs}$ $34.4, t(558.7)=-2.30, p=.02)$ and better educated $(76 \%$ vs. $64 \%$ with university-entrance diploma, $\left.\chi^{2}(6)=20.51, p=.002\right)$ than the drop-out sample.

\section{Measures}

\section{General self-control}

General self-control was measured with a German translation of the Brief Self-Control Scale (BSCS, Tangney et al., 2004; available at www.uni-konstanz.de/diagnostik/research_measures.htm). The BSCS consists of 13 items such as 'I am good at resisting temptations' ( $\alpha=.81$ ) with a five-point rating scale with [1] 'not at all like me' and [5] 'very much like me'.

\section{Body weight control motive}

Four items assessed body weight control as food choice motive ( $\alpha=.89$ ) with responses ranging from [1] 'never' to [7] 'always': 'I choose certain food items because they are low in calories', 'I choose certain food items because they are low in fat', 'I choose certain food items because I want to lose weight', and 'I choose certain food items to keep my weight'.

\section{Affect regulation motive}

Five items assessed the extent of affect regulation as food choice motive $(\alpha=.90)$ : 'I eat because I am frustrated', 'I eat because I am sad', 'I eat to distract me', 'I eat because I am stressed', and 'I eat to cheer me up', with responses ranging from [1] 'never' to [7] 'always'.

\section{Dietary behavior}

Dietary behavior was assessed with the validated food frequency questionnaire (Winkler \& Döring, 1998, 1995). Participants were asked how often they eat on average food items from 15 different selected food categories (e.g. whole meal products, vegetables, fruits, chocolate, cake, meat, and salty snacks) with [6] 'nearly once a day' and [1] 'never'. These 15 food categories were accumulated into a food frequency index reflecting dietary quality with a possible range of $0-30$. According to the recommendation of the German Nutritional Society and norm values for German samples on the basis of the WHO MONICA Augsburg Dietary Survey (cf. Winkler \& Döring, 1995; Winkler, Döring, \& Keil, 1991), scores of 13 or below indicate an unfavorable dietary pattern, scores greater than 13 and lower than 16 a regular dietary pattern, and scores of 16 or higher an optimal dietary pattern.

\section{Analytical procedure}

Missing data were imputed using the Expectation Maximization algorithm in SPSS 17.0 (cf. Gold \& Bentler, 2000). Missing values were below $5 \%$ for all variables. Structural equation models were computed with Mplus 5.1. Latent variables were based on indicators at the item level for both food choice motives. For general selfcontrol, indicators were based on parcels which were created by the random assignment method (Little, Cunningham, Shahar, \& Widaman, 2002). Parcels have a lower error variance and are, thus, more reliable than single indicators (Bandalos \& Finney, 2001). Items of the three independent variables were $z$-standardized to test the interactions.

Model fit was assessed by the comparative fit index (CFI), the Tucker-Lewis index (TLI), and the root-mean-square error of approximation (RMSEA). A good fit is indicated by a CFI and TLI greater than .90 , a RMSEA value smaller than .08 , a lower bound $90 \%$ confidence interval close to zero, and an upper bound $90 \%$ confidence interval not exceeding .10 (Tabachnick \& Fidell, 2001). Because the $\chi^{2}$ statistic is sample-size dependent, the $\chi^{2} / d f$ ratio was additionally calculated with a $\chi^{2}$ not larger than $2-5$ times the degrees of freedom indicating a good fit (Bollen \& Long, 1993).

\section{Results}

Behavior specific and general self-control resources, i.e., the tendency for body weight control and capacity for self-control, did not significantly covary (cf. Table 1 ). Interestingly, both food choice motives were positively related. Specifically, people with a tendency to eat in order to cope with negative affect had also a significantly higher tendency to control their body weight. Furthermore, while both the motivation for body weight control

Table 1

Correlations between study variables $(N=761)$.

\begin{tabular}{|c|c|c|c|c|}
\hline & General self-control & Body weight control motive & Affect regulation motive & Food frequency index ${ }^{a}$ \\
\hline General self-control & 1.00 & & & \\
\hline Body weight control motive & -.03 & 1.00 & & \\
\hline Affect regulation motive & $-.43^{\cdots}$ & $.30^{\cdots *}$ & 1.00 & \\
\hline
\end{tabular}

${ }^{a}$ Higher values indicate a healthier food intake.

... $p<.01$.

$p<.001$. 
and the general capacity of self-control were positively correlated with a healthy dietary pattern, the latter correlation coefficient was significantly greater with Fisher's $Z=3.25, p<.01$. Moreover, the affect regulation motive was negatively related to a healthy dietary pattern. This correlation coefficient differed again significantly from the other two with Fisher's $Z \geq 5.29, p<.001$.

To estimate the relative impact of general self-control, the motivation for body weight control and affect regulation, two conceptually different structural equation models were computed. In the first model, the independent additive effects of the three predictors on healthy dietary behavior were tested. In the second model, compensatory effects were examined, testing the hypothesis whether a high degree of general or behavior specific self-control may compensate a high tendency to regulate negative affect through the consumption of high caloric, palatable food.

In Model 1, the three predictors, general self-control, the motivation for body weight control, and affect regulation were specified as intercorrelated latent variables and dietary behavior as a manifest variable. Model 1 yielded a good fit, $\chi^{2}(99)=396, \chi^{2}$ । $d f=4, \mathrm{CFI}=.95, \mathrm{TLI}=.94, \mathrm{RMSEA}=.06(90 \% \mathrm{CI}=.056, .069)$. The results showed, that a higher general capacity for self-control was associated with a healthier dietary behavior $(\beta=.25, p<.001)$. The same holds true for the behavior specific self-control measure, the motivation for body weight control $(\beta=.15, p<.001)$. In contrast, the tendency to regulate negative affect through eating had a hindering effect, confirming its role as push factor. Specifically, the greater the tendency of the participants was to regulate negative affect through eating, the less healthy was their dietary pattern $(\beta=-.09, p=.04)$. Thus, all three predictors explained substantial variance of dietary behavior.

In Model 2, interaction terms of the three variables were added. However, no interaction term reached statistical significance. Unstandardized regression weights ranged from -.25 to .31 , $p>$.09. Thus, no compensatory or synergistic effects were observed.

A final analysis determined the absolute degree of healthiness of the dietary pattern, based on German reference norms (Winkler \& Döring, 1995) in dependence of the three predictor variables. Towards this end, high and low scoring groups were defined as being one standard deviation above or below the sample mean of the respective variable (cf., Nederkoorn et al., 2009). Mean levels are based on the $\beta$ s and prediction equation derived from Model 1. While the dietary behavior was commonly in the regular or optimal norm range (see Fig. 1), clear differences in the healthiness of diet were observed in dependence of the three predictor variables. A dietary pattern in the optimal range was only observed for participants with both a high general self-control and a high motivation for body weight control. Interestingly, even these "high

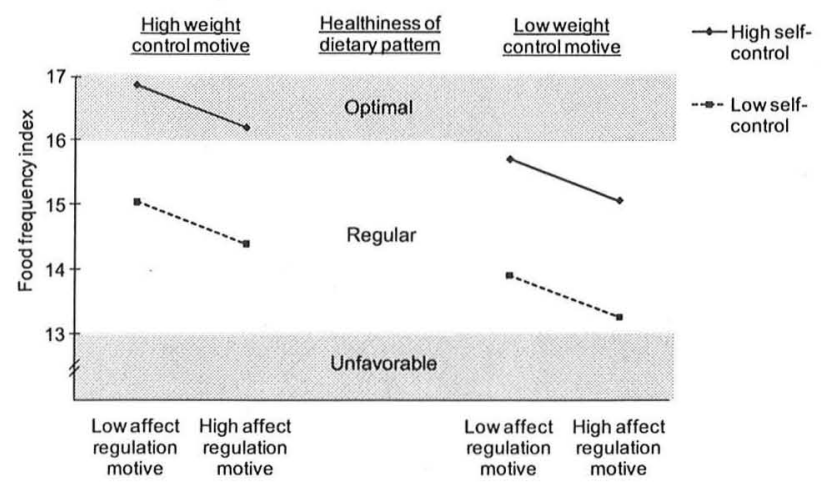

Fig. 1. Food frequency index as a function of general self-control, body weight control motive, and affect regulation motive. self-regulators' showed a decrease in healthy eating when they had simultaneously a high tendency to regulate negative affective states through comfort eating. A further noteworthy finding is that a high general self-control had a greater facilitating effect on a healthy diet as compared to a high motivation for body weight control. Finally, the relative lack of self-regulatory resources combined with a high tendency to regulate negative affect through comfort eating was associated with the least favorable dietary pattern.

\section{Discussion}

The present study revealed the simultaneous contributions of general self-control, specific body weight control motive, and affective comfort eating on dietary healthiness in a sample of women. Somewhat surprisingly, of the two pull factors facilitating a healthy diet, the general capacity for self-regulation showed stronger effects than the more behavior specific body weight control motive. Furthermore, a high tendency to regulate negative affect through comfort eating lowered dietary healthiness consistently with the notion of a push factor. Overall, the healthiness of diet was systematically related to independent push and pull factors of food choice and eating.

Focusing on snacking behavior, previous research already suggested that both self-control and body weight control motive modulate food choice (e.g. Glanz et al., 1998; Junger \& van Kampen, 2010). These findings are not limited to a highly specific food category, but seem to extend to a broad range of food categories as the present study used a comprehensive and validated measure of dietary healthiness. Furthermore, assessing both pull factors provides important insights into their relationship and relative importance for dietary healthiness. Self-control and body weight control motive made independent contributions to dietary healthiness, and accordingly represent two non-redundant facets of self-regulatory resources facilitating a healthy diet. Interestingly, in the present sample, general self-control showed a significantly stronger relationship to dietary healthiness than the behavior specific motivation for body weight control suggesting that 'self-control generalists' are better off than 'self-control specialists'.

Given that self-control can be improved, the current data have implications for the promotion of healthy eating. For instance, a recent study showed that the training of a selfcontrol strategy was effective in reducing strong habits of unhealthy snacking (cf. Tam, Bagozzi, \& Spanjol, 2010). Furthermore, the experience of self-control in one domain can have 'spill-over' effects to unrelated domains. A longitudinal study showed that through a regulatory exercise phase, participants showed improvements in the regulation in a wide range of health-related behaviors such as a decrease in smoking and alcohol consumption and an increase in healthy eating (Oaten \& Cheng, 2006). Thus, there is evidence that at least domain-specific self-control can be improved and that improved self-control leads to a healthier dietary pattern. However, rather than supporting a 'one size fits all' approach, the current findings suggest the identification and monitoring of tailored strategies to promote healthy eating depending on the individual profile of push and pull factors. Consistent with the 'value from fit' view (cf. Tam et al., 2010), effectiveness of promotion strategies targeting the domain-specific control of body weight may depend on a corresponding high personal disposition for self-control. Conversely, people with a low dispositional self-control may profit more from the implementation of external control strategies. Overall, interventions need not only to focus on the desire and capacity for body weight control but also on the general capacity for self-control. 
The current study supports the notion that a high tendency to regulate negative affect through comfort eating lowered dietary healthiness in women. Inconsistent findings regarding the relationship of emotional eating and unhealthy diet have been attributed recently to the measurement of emotional eating. Specifically, the emotional eating subscale of the Dutch Eating Behavior Questionnaire (van Strien, Frijters, Bergers, \& Defares, 1986) is considered to primarily measure beliefs about the relation of emotion and eating rather than the tendency to regulate negative affective states through comfort eating (Adriaanse et al. 2011). Items used in the present study specifically assess the tendency to regulate negative affect through eating. Thus, the current measure of the affect regulation motive appears useful to assess emotional eating and is predictive for unhealthy dietary behavior.

Beyond methodological issues, the present study has further implications why previous studies were inconsistent. Specifically, emotional eating is but one factor contributing to food choice and dietary healthiness. The simultaneous consideration of the push and pull factors in the present study suggests that a high tendency to regulate negative affect by eating can be counteracted by high self-control. This reasoning is based on the finding that high emotional eating was associated with less general self-control but increased motivation for body weight control. Accordingly, the relationship between emotional eating and dietary healthiness in a given study may depend on the proportion of participants with high or low self-control. Overall, general self-control seems to be an important moderator of food choice and healthy diet, opposing the push factor emotional eating, and influencing the extent to which foods are considered tempting (de Ridder \& de Wit, 2006)

Some limitations of the present study need to be considered. Healthy eating was defined according to the recommendations of the German Nutritional Society (Winkler \& Döring, 1995). However, at present, there is no commonly accepted definition of healthy or unhealthy eating, and thus, the classification is debatable. All variables were self-reported and the complementary assessment of objective measures is desirable. Importantly validation data for the used food frequency questionnaire showed good agreement with a continuous 7-day diary record (Winkler \& Döring, 1995). Causal inferences cannot be drawn on the basis of the present cross-sectional data. And finally, only German women were included in the present study. Therefore, the findings cannot be generalized across gender or cultures (cf. Renner et al., 2008).

\section{References}

Adriaanse, M. A., de Ridder, D. T. D., \& Evers, C. (2011). Emotional eating. Eating when emotional or emotional about eating? Psychology $E^{\prime}$ Health, 26(1), 2339doi:10.1080/08870440903207627.

Bandalos, D. L., \& Finney, S. J. (2001). Item parceling issues in structural equation modeling. In G. A. Marcoulides \& R. E. Schumacker (Eds.), New developments and techniques in structural equation modeling (pp. 269-296). Mahwah, NJ, US: Lawrence Erlbaum Associates Publishers.

Bollen, K., \& Long, J. (1993). Testing structural equation models. Newbury Park, CA: Sage. de Ridder, D., \& de Wit, J. (2006). Self-regulation in health behavior. West Sussex: John Wiley \& Sons Ltd.

Eertmans, A., Victoir, A., Vansant, G., \& van den Bergh, O. (2005). Food-related personality traits, food choice motives and food intake. Mediator and moderator relationships. Food Quality and Preference, 16(8), 714-726doi:10.1016/j foodqual.2005.04.007.
Gibson, C. L, Ward, J. T., Wright, J., Beaver, K. M., \& Delisi, M. (2010). Where does gender fit in the measurement of self-control. Criminal Justice and Behavior, 37(8), 883903doi: $10.1177 / 0093854810369082$.

Glanz, K., Basil, M., Maibach, E., Goldberg, J., \& Snyder, D. (1998). Why Americans eat what they do. Taste, nutrition, cost, convenience, and weight control concerns as influences on food consumption. Journal of the American Dietetic Association, 98(10), 1118-1126doi:10.1016/S0002-8223(98)00260-0.

Gold, M. S. \& Bentler, P. M. (2000). Treatments of missing data. A Monte Carlo comparison of RBHDI, iterative stochastic regression imputation, and expectation-maximization. Structural Equation Modeling, 7(3), 319-355doi:10.1207/ s15328007sem0703_1.

Habhab, S., Sheldon, J. P., \& Loeb, R. C. (2009). The relationship between stress, dietary restraint, and food preferences in women. Appetite, 52(2), 437-444doi:10.1016/ j.appet.2008.12.006

Junger, M, \& van Kampen, M. (2010). Cognitive ability and self-control in relation to dietary habits, physical activity and bodyweight in adolescents. International Journal of Behavioral Nutrition and Physical Activity, 7(22), 1-12doi:10.1186/ 1479-5868-7-22.

Konttinen, H., Männistö, S., Sarlio-Lähteenkorva, S., Silventoinen, K., \& Haukkala, A. (2010). Emotional eating, depressive symptoms and self-reported food consumption. A population-based study. Appetite, 54(3), 473-479doi:10.1016/ j.appet.2010.01.014

Little, T. D, Cunningham, W. A., Shahar, G., \& Widaman, K. F. (2002). To parcel or not to parcel. Exploring the question, weighing the merits. Structural Equation Modeling, 9(2), 151-173doi:10.1207/S15328007SEM0902 1.

Macht, M., \& Mueller, J.(2007). Interactive effects of emotional and restrained eating on responses to chocolate and affect. Journal of Nervous and Mental Disease, 195(12), 1024-1026doi:10.1097/NMD.0b013e31815c0878.

Nederkoorn, C., Guerrieri, R., Havermans, R. C., Roef, A., \& Jansen, A. (2009). The interactive effect of hunger and impulsivity on food intake and purchase in a virtual supermarket. Interactive effect of hunger and impulsivity. International Journal of Obesity, 33(8), 905-912doi:10.1038/ijo.2009.98

Oaten, M., \& Cheng, K. (2006). Improved self-control. The benefits of a regular program of academic study. Basic and Applied Social Psychology, 28(1), 1-16doi:10.1207| s15324834basp2801_1.

Remick, A. K., Polivy, J., \& Pliner, P. (2009). Internal and external moderators of the effect of variety on food intake. Psychological Bulletin, 135(3), 434-451doi:10.1037| a0015327.

Renner, B., Kwon., S., Yang, B. H., Paik, K.-C., Kim, S. H., Roh, S., et al. (2008). Socialcognitive predictors of dietary behaviors in South Korean men and women. International Journal of Behavioral Medicine, 15(1), 4-13doi:10.1080 10705500701783785

Steptoe, A., \& Wardle, J. (1999). Motivational factors as mediators of socioeconomic variations in dietary intake patterns. Psychology \& Health, 14(3), 391-402.

Steptoe, A., Pollard, T. M., \& Wardle, J. (1995). Development of a measure of the motives underlying the selection of food. The food choice questionnaire. Appetite, 25(3) 267-284doi:10.1006/appe0061.

Tabachnick, B. G., \& Fidell, L. S. (2001). Using multivariate statistics Boston: Allyn and Bacon.

Tam, L., Bagozzi, R. P., \& Spanjol, J. (2010). When planning is not enough. The selfregulatory effect of implementation intentions on changing snacking habits. Health Psychology, 29(3), 284-292doi:10.1037/a0019071.

Tangney, J. P., Baumeister, R. F., \& Boone, A. L. (2004). High self-control predicts good adjustment, less pathology, better grades, and interpersonal success. Journal of Personality, 72(2), 271-324doi:10.1111/j.0022-3506.2004.00263.

van Strien, T, Frijters, J. E., Bergers, G. P., \& Defares, P. B. (1986). The Dutch Eating Behavior Questionnaire (DEBQ) for assessment of restrained, emotional, and external eating behavior. International Journal of Eating Disorders, 5(2), 295315doi:10.1002/1098-108x(198602)5:2<295::aid-eat2260050209>3.0.co;2-t.

Verplanken, B., Herabadi, A. G., Perry, J. A., \& Silvera, D. H. (2005). Consumer style and health. The role of impulsive buying in unhealthy eating. Psychology \& Health 20(4), 429-441doi:10.1080/08870440412331337084.

Winkler, G., \& Döring, A. (1995). Kurzmethoden zur Charakterisierung des Ernährungsmusters. Einsatz und Auswertung eines Food-Frequency-Fragebogens [Brief methods for describing eating patterns. Application and analysis of a food frequency questionnaire]. Ernährungsumschau [Dietary Survey], 42(8), 289-291.

Winkler, G., \& Döring, A. (1998). Validation of a short qualitative food frequency lis used in several German large scale surveys. Zeitschrift für Ernährungswissenschaft Uournal of Nutrition Sciencel, 37(3), 234-241.

Winkler, G., DÖring, A., \& Keil, U. (1991). Selected nutrient intakes of middle-aged men in southern Germany. Results from the WHO MONICA Augsburg Dietary Survey of 1984/85. Annals of Nutrition and Metabolism, 35(5), 284-291doi:10.1159/ 000177658. 